difficult exchange transfusion. In the first of these two cases there was a positive blood culture for $E$. coli associated with bowel necrosis extending from the caecum to the descending colon. Our second case had diarrhoea for seven days, which preceded the onset of abdominal distension and peripheral circulatory collapse owing to necrosis and perforation of the terminal ileum only. Unfortunately both these infants died without laparotomy being undertaken, and at necropsy we were able to demonstrate antemortem thrombi in the ductus venosus and portal vein in the first and in the portal and splenic veins in the second. We note that in the series quoted there is no comment on the state of the portal vein in those infants who died. A fuller report is being prepared for publication.-We are, etc.,

\section{E. S. MUCKLOW.}

D. J. DE SA'.

Department of Paediatrics

United Oxford Hospitals,

Oxford.

\section{Screening for Cervical Cancer}

SIR,-As practitioners we have been asked to read a circular letter from the Ministry of Health on the population screening for cancer of the cervix ${ }^{1}$ which was sent to all senior administrative medical officers and secretaries of regional boards in August of this year.

We are amazed that the Ministry either refuses to acknowledge or accept that its policy is erroneous, and that it loses the support of those of us who are working in the field of cytology. We have just summarized the histological findings in the last 214 consecutive patients who were shown to have either dysplasia or carcinoma-in-situ of the cervix when a cone biopsy was performed for a positive smear. These show that out of this total no fewer than 64 were below the age of 35 years. These patients were taken from antenatal, gynaecological, family planning, venereal disease, and well-women clinics. No account was taken of their age, but every woman in whom a routine pelvic examination was being made also had a routine cervical scrape. These figures are broken down in age groups (Table). This does not take account of those patients who during such a routine investigation were also found to have carcinoma of the cervix (there was one aged 18 years) or other gynaecological findings warranting treatment. Our figures, as in those of the British Columbia experiment, ${ }^{2}$ show that there is a peak in the age prevalence of this disease at around 35 years, but we also see that the disease is just as likely to occur under, as it is over, the age of 35 .

\begin{tabular}{c|c}
\multicolumn{2}{c}{ TABLE } \\
\hline Age & $\begin{array}{c}\text { Patients with Pre- } \\
\text { invasive Lesions of } \\
\text { Cervix }\end{array}$ \\
\hline Below 20 & 2 \\
$20-25$ & 20 \\
$26-30$ & 38 \\
$31-35$ & 34 \\
$36-40$ & 51 \\
$41-45$ & 39 \\
$46-50$ & 16 \\
$51-55$ & 9 \\
Over 55 & 5
\end{tabular}

The difficulty in persuading a woman to have a vaginal examination in the absence of symptoms is well known, and most practitioners agree that a cervical cytology smear should be taken at the time of any routine examination in any clinic, and that this should include all age groups of women at risk-that is, from the age of puberty onwards. It is much more relevant to offer a woman a cervical smear if she commenced coitus at the age of 14 years with a variety of boy friends than if she is a married woman over the age of 35 with one, possibly two, children and only one husband. This simple fact the Ministry have persistently refused to accept, and what is more they have the audacity to offer a miserable fee to the general practitioner and set an age limit which positively discourages him from taking a smear below the age of 35 . What is more, should he think it necessary, or indicated on clinical grounds, to take a further cervical smear before five years have elapsed he will not receive a further fee. This ignores completely the fact that a woman may present new vaginal symptoms within less than one year. Small wonder that the Ministry finds it necessary to send a circular to practitioners admonishing them for their lack of enthusiastm in cervical cytology.

Many women, and indeed many general practitioners, are firmly of the opinion that the Ministry policy implies that it is not necessary to have a smear below the age of 35 . As our figures show, $30 \%$ of proved but previously unsuspected pre-invasive lesions of cervix occur below this age in what are readily screened groups. We sincerely hope that members of the profession are not taken in by this second-rate cytology service.-We are, etc.,

\section{A. J. LUCAS.}

MARY Glover. M. E. AtTwood.

Birmingham Maternity Hospital,

Birmingham 15.

REFERENCES

Ministry of Health Circular H/C1/69 Bryans, F. E., Boyes, D. A., and Fidier, H. K.
Amer. $\dot{y}$. Obstet. Gynec., 1964, 88, 898 .

\section{Inhibition of Lactation by Oestrogens}

SIR,-Professor D. Llewellyn-Jones claims in his letter ( 9 November, p. 387) that inhibition of lactation is best effected by oestrogens. In his series, however, $53 \%$ of the patients only had lactation temporarily suppressed or postponed. Further oestrogens were required in $30 \%$, and there are no figures on the 42 day follow-up of the patients treated with the placebo. Other series ${ }^{1-3}$ have been published in which oestrogens are shown to have little or no advantage over treatment with mild analgesics and adequate breast support. Furthermore they indicate that it is patients treated with oestrogens who are most liable to develop painful lactating breasts after discharge from hospital.

We have recently conducted a double-blind trial using stilboestrol and placebo tablets. Eighty-six mothers who did not wish to breast feed were given one tablet thrice daily for two days, followed by one tablet twice daily for two days, and one tablet daily for two days. Fortyseven patients received a total of $60 \mathrm{mg}$. stilboestrol and 44 received the placebo. We had previously found that a larger dose gave no advantage. One patient, who had taken the placebo, subsequently required Nepenthe, but the remainder had either no analgesic or paracetamol. More of the group given placebo received paracetamol (19 against 7) but more of those given oestrogens required further oestrogens from their general practitioners (9 against 2 ). It is of interest that several patients having started oestrogens decided to breast feed and did so without difficulty.

The exhibition of oestrogens for the inhibition or suppression of lactation seems to be based largely on custom and theory. The published series suggest that they may only delay the onset of lactation and fail to suppress it once it is established. Many doctors, nurses, and patients have an almost religious faith in oestrogens, and the quantity prescribed annually for this purpose must be considerable. In addition there may be an increased risk of thrombo-embolism. ${ }^{45}$ Some units have already discontinued the use of oestrogens for this purpose without adverse results, and I hope that others may be stimulated to follow suit, and possibly also to undertake more extensive trials.

I am grateful to Mr. Bryn, Miss A. Commings, Sister V. Rudwick, and the staff of the department for their cooperation.

-I am, etc.,

The Middlesex Hospital,

S. J. Steele.

London W.1.

\section{REFBRENCES}

Gold, J. J., and Cohen, M. R., Obstet. and Gynaec., 1959 13, 413.
Auld, M. G., Midwife and Health Visitor, 1967,

Mac'403. 1965, 2, 623. Campbell, H., and Turnbull, A. C. Lancet, 1967, 2, 287.

Daniel, D. G., Bloom, A. L.; Giddings, J. C., f., $1968,1,801$.

\section{Cause of Unexplained Anaemia}

SIR,-Drs. C. M. Stanbridge and P. C. Srivastava (26 October, p. 252) stressed the importance of quantitating haemoglobin $\mathbf{A}_{2}$ for investigating the cause of unexplained anaemia among the immigrants in this country. They had picked up four cases of thalassaemia and thought that this trait would be highest in India and West Pakistan. Without sufficient statistical data, no one would accept this view. The writers did not emphasize the frequent occurrence of thalassaemia among people originating in the Mediterranean basin who might as well be the immigrant in this country and suffering from "unexplained anaemia."

The history, physical examination, and blood film appearance are usually sufficient to suggest the diagnosis of anaemia. We do not jump on to serum iron estimation and bone marrow study. Marked hypochromia is present in iron-deficiency anaemia as well as in thalassaemia major. ${ }^{1}$ In thalassaemia the serum iron is normal or raised but not lowered. ${ }^{1}$ The low serum iron and stainable iron in the marrow suggest iron-deficiency anaemia, but this diagnosis is not complete without demonstrating the source of blood loss from the body. I wonder whether those immigrant patients had full investigation before iron therapy was started.

The writers commented that the incidence of $\beta$-thalassaemia would seem to be highest 